\title{
Molecular Gold Nanocluster Auts6 Showing Metallic Electron Dynamics
}

Feng Hu, ${ }^{\dagger}$ Zong-Jie Guan, ${ }^{\dagger}$ Gaoyuan Yang, ${ }^{\ddagger}$ Jia-Qi Wang, ${ }^{\dagger}$ Jiao-Jiao Li, ${ }^{\dagger}$ ShangFu Yuan, ${ }^{\dagger}$ Gui-Jie Liang ${ }^{*},{ }^{*}$ and Quan-Ming Wang ${ }^{*}{ }^{\dagger}$

${ }^{\dagger}$ Department of Chemistry, Key Laboratory of Organic Optoelectronics and Molecular Engineering of the Ministry of Education, Tsinghua University, Beijing, 100084 (P. R. China)

${ }^{\ddagger}$ Hubei Key Laboratory of Low Dimensional Optoelectronic Materials and Devices, Hubei University of Arts and Science, Xiangyang 441053, (P. R. China) 


\section{Contents}

\section{Physical measurements}

\section{Supporting figures}

Figure S1. ${ }^{1} \mathrm{H}$ NMR spectrum of $\mathrm{Ph}_{4} \mathrm{PCl}$ and $\mathbf{A u}_{156}$ in $\mathrm{CD}_{3} \mathrm{OD}$.

Figure S2. The splitting of the seven $2 \mathrm{~F}$ orbitals of $\mathbf{A} \mathbf{u}_{156}$ under $D_{5 \mathrm{~d}}$ symmetry and the population of the valence electrons.

Figure S3. The view of innermost shell $\mathrm{Au}_{46}$ in the kernel of $\mathbf{A u}_{156}$.

Figure S4. The view of second shell $\mathrm{Au}_{50}$ in the kernel of $\mathbf{A} \mathbf{u}_{156}$.

Figure S5. The view of third shell $\mathrm{Au}_{30}$ in the kernel of $\mathbf{A} \mathbf{u}_{\mathbf{1 5 6}}$.

Figure S6. The view of fourth (outmost) shell $\mathrm{Au}_{30}$ in the kernel of $\mathbf{A u}_{156}$.

Figure S7. Two different alkynyl-gold coordination motifs found in $\mathbf{A} \mathbf{u}_{156}$ surface.

Figure S8. ${ }^{19} \mathrm{~F}$ NMR spectrum of $\mathbf{A u}_{156}$ in $\mathrm{CD}_{3} \mathrm{OD}$.

Figure S9. UV-Vis-NIR absorption spectrum of $\mathbf{A u}_{156}$ in $\mathrm{CH}_{2} \mathrm{Cl}_{2}$.

Figure S10. TA data maps pumped at $400 \mathrm{~nm}$ with different pump power.

Figure S11. The relationship between the maximum intensity and pump power (pumped at $400 \mathrm{~nm}$ ).

Figure S12. The absorption spectra of $\mathbf{A u}_{156}$ before and after TA experiments pumped at $400 \mathrm{~nm}$.

Figure S13. The absorption spectra of $\mathbf{A u}_{156}$ before and after TA experiments pumped at $700 \mathrm{~nm}$.

Figure S14. The relationship between the maximum intensity and pump power (pumped at $700 \mathrm{~nm}$ ).

Figure S15. TA data maps pumped at $700 \mathrm{~nm}$ with different pump power.

Figure S16. TA data maps pumped at $500 \mathrm{~nm}$ with different pump power.

Figure S17. Transient absorption data of $\mathbf{A u}_{156}$ pumped at $500 \mathrm{~nm}$ in $\mathrm{CH}_{2} \mathrm{Cl}_{2}$.

Figure S18. The absorption spectra of $\mathbf{A u}_{156}$ before and after TA experiments pumped at $500 \mathrm{~nm}$.

Figure S19. The relationship between the maximum intensity and pump power (pumped at $500 \mathrm{~nm}$ ).

Figure S20. TA data maps pumped at $600 \mathrm{~nm}$ with different pump power.

Figure S21. Transient absorption data of $\mathbf{A u}_{156}$ pumped at $600 \mathrm{~nm}$ in $\mathrm{CH}_{2} \mathrm{Cl}_{2}$.

Figure S22. The absorption spectra of $\mathbf{A u}_{156}$ before and after TA experiments pumped at $600 \mathrm{~nm}$.

Figure S23. The relationship between the maximum intensity and pump power (pumped at $600 \mathrm{~nm}$ ).

Figure S24. The metal kernel of Au nanoclusters in core-shell structure.

Figure S25. UV-Vis absorption spectra of Au $\mathbf{u}_{156}$ products and $\mathbf{A} \mathbf{u}_{156}$ crystals.

Figure S26. ESI-MS of $\mathbf{A u}_{156}$ products in negative mode.

Table S1. A summary of Au-Au bond lengths in $\mathbf{A} \mathbf{u}_{156}$.

Table S2. A summary of Au-C bond lengths in $\mathbf{A} \mathbf{u}_{156}$.

Table S3. Delay lifetime of $\mathbf{A u}_{156}$ on TA measurement with $400 \mathrm{~nm}$ laser excitation.

Table S4. Delay lifetime of $\mathbf{A u}_{156}$ on TA measurement with $700 \mathrm{~nm}$ laser excitation.

Table S5. Delay lifetime of $\mathbf{A} \mathbf{u}_{\mathbf{1 5 6}}$ on TA measurement with $500 \mathrm{~nm}$ laser excitation.

Table S6. Delay lifetime of $\mathbf{A u}_{156}$ on TA measurement with $600 \mathrm{~nm}$ laser excitation. 


\section{Physical measurements}

UV-Vis-NIR absorption spectrum was recorded on cary5000. Mass spectrum in negative mode was recorded on a Waters Q-TOF mass spectrometer using a Z-spray source. The sample was directly infused into the chamber at $5 \mu \mathrm{L} / \mathrm{min}$. The source temperature was preserved at $70^{\circ} \mathrm{C}$, the spray voltage was $2.20 \mathrm{kV}$ and the cone voltage was adjusted to $60 \mathrm{~V}$. Mass spectrum in positive mode was recorded on a Bruker micro TOF-QII. The ESI sample was prepared by dissolving the nanoclusters in $\mathrm{CH}_{2} \mathrm{Cl}_{2}$. The NMR data were recorded on a JNM-ECA-600 spectrometer (600 MHz) for ${ }^{1} \mathrm{H}$ NMR and ${ }^{19} \mathrm{~F}$ NMR. Differential Pulse Voltammetry was performed with a CHI 660E Electrochemical workstation at room temperature using a $0.3 \mathrm{~mm}-\mathrm{Pt}$ disk working electrode, a Pt wire counter electrode and a $\mathrm{Ag} / \mathrm{Ag}^{+}$ reference electrode ( $-0.22 \mathrm{~V}$ vs. $\mathrm{Fc}^{+} / \mathrm{Fc}$ couples). The working electrode was polished with 0.3 micron $\mathrm{Al}_{2} \mathrm{O}_{3}$ slurries before use. Reference electrode is filled with $\mathrm{AgNO}_{3}(10 \mathrm{mM})$ in acetonitrile as supporting electrolytes. All solutions were degassed with high-purity $\mathrm{N}_{2}$ gas during the experimental procedure with $0.1 \mathrm{M} \mathrm{Bu}_{4} \mathrm{NPF}_{6}$ in DCM solution as the blank. Background potential scans in electrolyte solutions were used to check for any spurious peaks. DPV scan was conducted at $20 \mathrm{mV} / \mathrm{s}$. All potentials are reported with respect to $\mathrm{Ag} / \mathrm{Ag}^{+}$electrode. Solutions from $\mathbf{A} \mathbf{u}_{156}$ crystals were used for the above tests including UV-Vis-NIR, ESI-TOF-MS, NMR and DPV.

\section{X-ray Crystallography}

Intensity data of $\left[\mathrm{Ph}_{4} \mathrm{P}\right]_{6}\left[\mathrm{Au}_{156}(\mathrm{C} \equiv \mathrm{CR})_{60}\right]$ were collected on a Rigaku Agilent SuperNova Dual system $(\mathrm{CuK} \alpha)$ at $100 \mathrm{~K}$. Absorption corrections were applied by using the program CrysAlis (multi-scan). The structure was solved by direct methods, and non-hydrogen atoms were refined anisotropically by leastsquares on F2 using the SHELXTL program. The hydrogen atoms of organic ligands were generated geometrically. SQUEEZE tool of PLATON was applied, due to large solvent voids in the structures. F atoms and solvent molecules were refined isotropically due to weak diffraction.

\section{Femtosecond Transient Absorption}

The femtosecond pump-probe TA measurements were performed using a regenerative amplified Ti:sapphire laser system (Coherent; $800 \mathrm{~nm}, 85 \mathrm{fs}, 7 \mathrm{~mJ} / \mathrm{pulse}$, and $1 \mathrm{kHz}$ repetition rate) as the laser source and a Helios spectrometer (Ultrafast Systems LLC). Briefly, the $800 \mathrm{~nm}$ output pulse from the regenerative amplifier was split in two parts with a 50\% beam splitter. The transmitted part was used to pump a TOPAS Optical parametric amplifier (OPA) which generated a wavelength-tunable laser pulse from $250 \mathrm{~nm}$ to $2.5 \mu \mathrm{m}$ as pump beam. $400 \mathrm{~nm}$ pump beam was made by frequency-doubling of one part of $800 \mathrm{~nm}$ beam in the BBO crystal. The reflected $800 \mathrm{~nm}$ beam was split again into two parts. One part with less than $10 \%$ was attenuated with a neutral density filter and focused into a $2 \mathrm{~mm}$ thick sapphire window to generate a white light continuum (WLC) used for probe beam. The probe beam was 
focused with an $\mathrm{Al}$ parabolic reflector onto the sample. After the sample, the probe beam was collimated and then focused into a fiber-coupled spectrometer with CMOS sensors and detected at a frequency of $1 \mathrm{KHz}$. A series of neutral-density filters was used to adjust the power of the pump beam. The pump beam was focused at the sample with a beam waist of about $300 \mu \mathrm{m}$. The delay between the pump and probe pulses was controlled by a motorized delay stage. The pump pulses were chopped by a synchronized chopper at $500 \mathrm{~Hz}$ and the absorbance change was calculated with two adjacent probe pulses (pump-blocked and pump-unblocked). Samples were vigorously stirred in all the measurements. The solution for TA measurements was prepared from $\mathbf{A} \mathbf{u}_{156}$ crystals. 


\section{Supporting figures}

a)
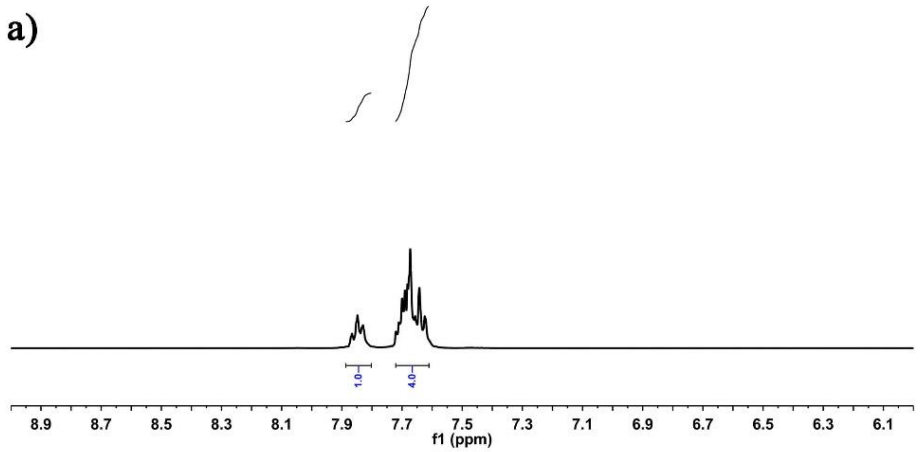

b)

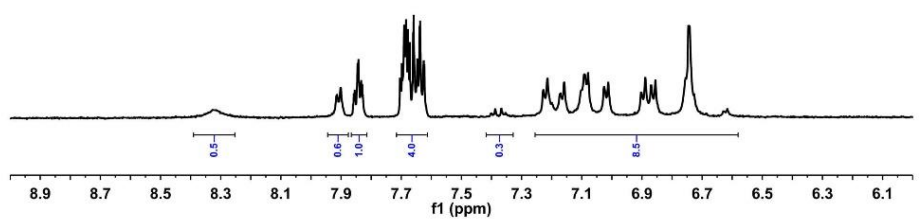

Figure S1. (a) ${ }^{1} \mathrm{H}$ NMR spectrum of $\mathrm{Ph}_{4} \mathrm{PCl}$ in $\mathrm{CD}_{3} \mathrm{OD}$. (b) ${ }^{1} \mathrm{H}$ NMR spectrum of $\mathbf{A u}_{156}$ in $\mathrm{CD}_{3} \mathrm{OD}$.

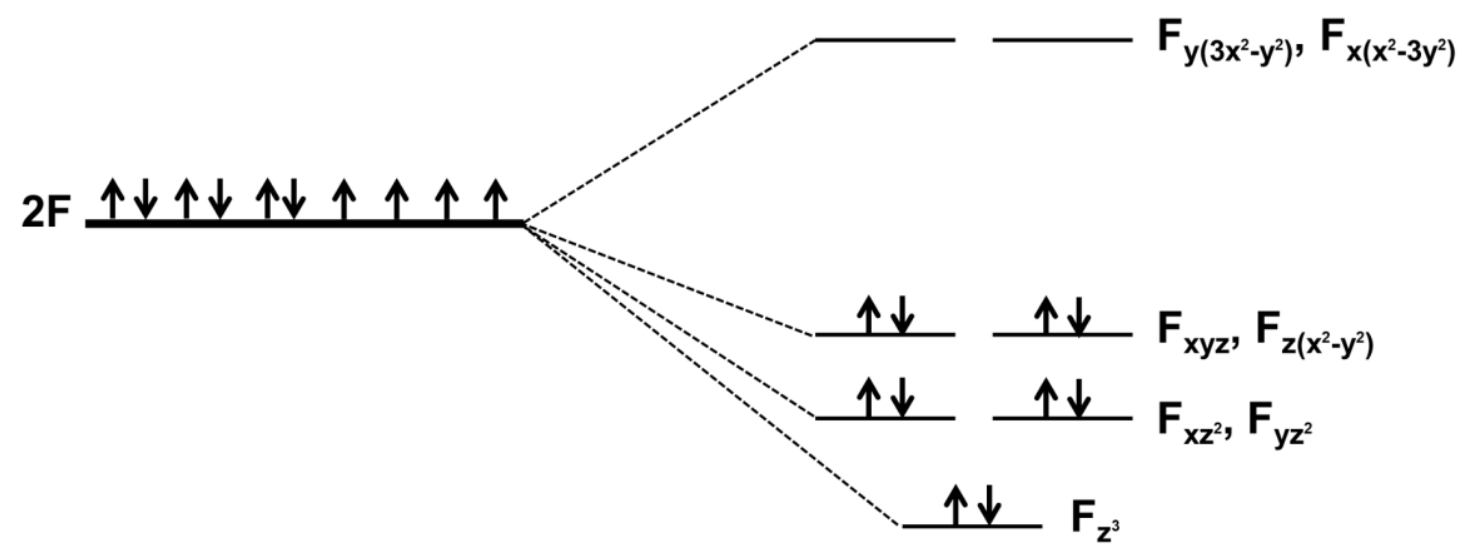

Figure S2. The splitting of the seven $2 \mathrm{~F}$ orbitals of $\mathbf{A} \mathbf{u}_{\mathbf{1 5 6}}$ under $D_{5 \mathrm{~d}}$ symmetry and the population of the valence electrons. 


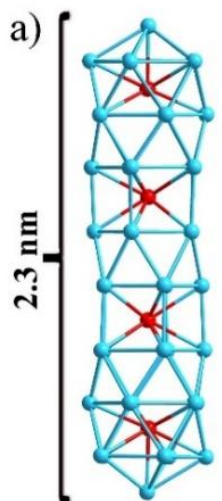

1st Shell b)

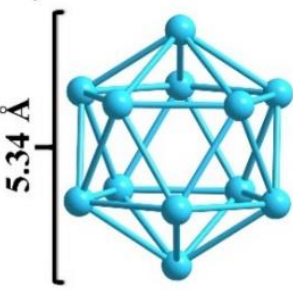

Icosahedron

$\mathrm{Au}_{12}$ c)

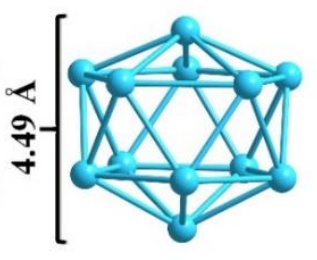

Flattened icosahedron $\mathrm{Au}_{12}$ d)

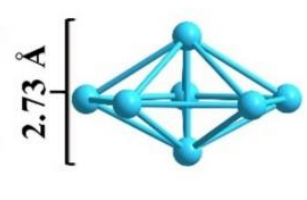

Pentagonal bipyramid

$\mathrm{Au}_{7}$

Figure S3. (a) Innermost shell $\mathrm{Au}_{46}$ is composed of an icosahedron $\mathrm{Au}_{12}$, two flattened icosahedrons $\mathrm{Au}_{12}$ and two pentagonal bipyramids $A u_{7}$. (b) Icosahedron $\mathrm{Au}_{12}$ with the length of $5.34 \AA$. (c) Flattened icosahedron $\mathrm{Au}_{12}$ with the length of $4.49 \AA$. (d) Pentagonal bipyramid $\mathrm{Au}_{7}$ with the length of $2.73 \AA$. (Red balls, Au atoms shared by polyhedrons)

a)

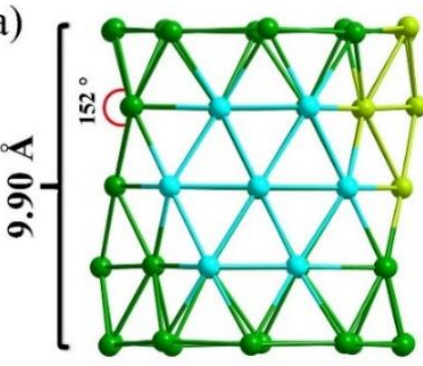

2 nd Shell

$\mathrm{Au}_{50}$

c)

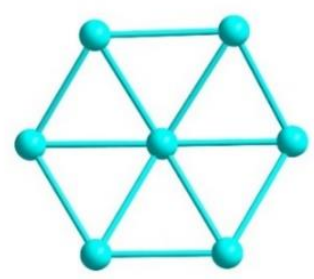

Hexagon

$\mathrm{Au}_{7}$

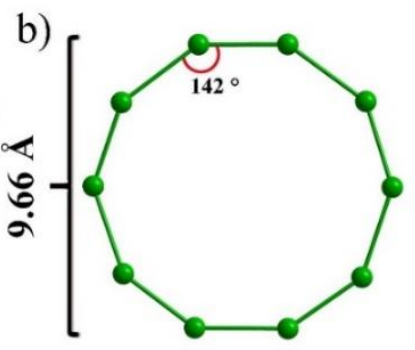

Ten-membered ring $\mathrm{Au}_{10}$

d)

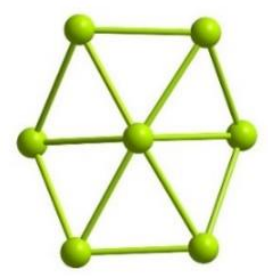

Distorted hexagon

$\mathrm{Au}_{7}$

Figure S4. (a) Second shell $\mathrm{Au}_{50}$ is composed of five staggered ten-membered rings $\mathrm{Au}_{10}$. (b) Tenmembered ring $\mathrm{Au}_{10}$ with a diameter of $9.90 \AA$. (c) Hexagon $\mathrm{Au}_{7}$ located on the waist of $\mathrm{Au}_{50}$. (d) Distorted hexagon $\mathrm{Au}_{7}$ located on the waist of $\mathrm{Au}_{50}$. 


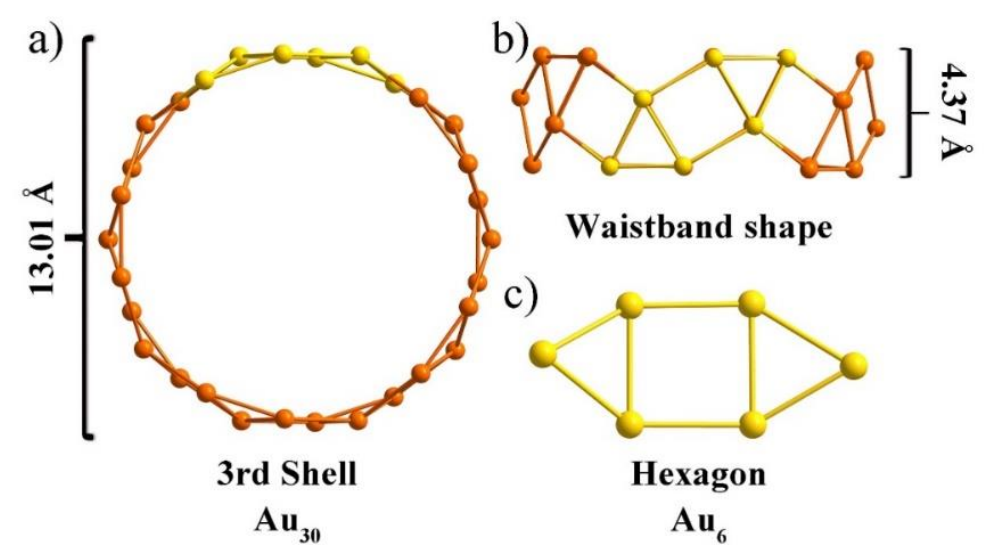

Figure S5. The top (a) and side (b) views of the third shell $\mathrm{Au}_{30}$ with a diameter of $13.01 \AA$. (c) Five hexagons $\mathrm{Au}_{6}$ make up the third shell $\mathrm{Au}_{30}$.
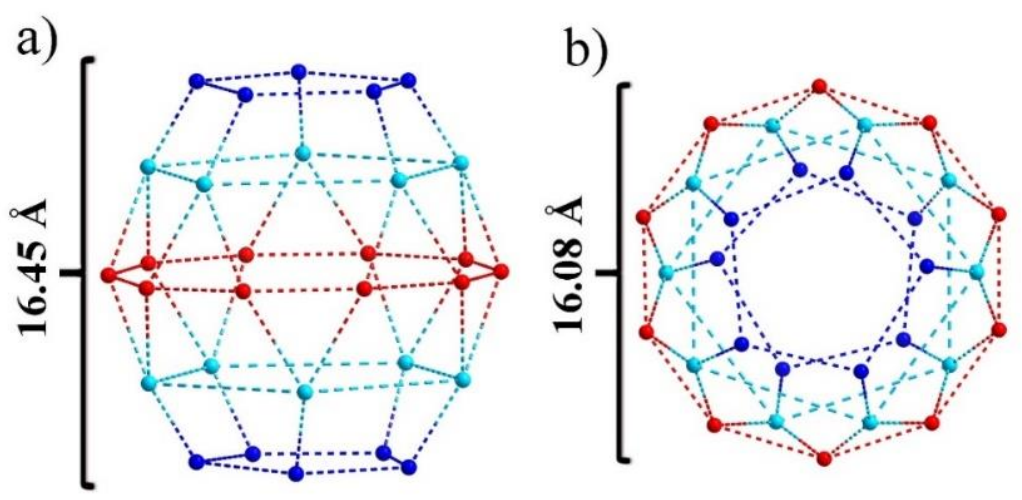

\section{4th Shell}

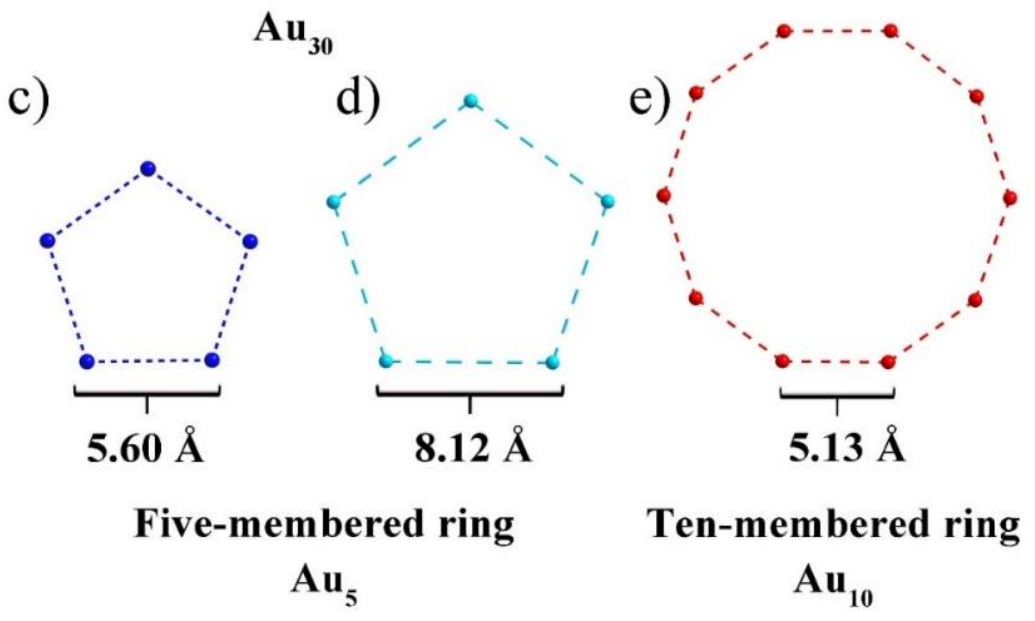

Figure S6. The top (a) and side (b) views of the fourth (outmost) shell contains 30 gold atoms. These $30 \mathrm{Au}$ atoms along with 60 alkynyl ligands form $30 \mathrm{RC} \equiv \mathrm{C}-\mathrm{Au}-\mathrm{C} \equiv \mathrm{CR}$ motifs on the surface of kernel $A_{126}$. (c) First layer pentagon $A_{4}$ with the side length of $5.60 \AA$. (d) Second layer pentagon $A_{5}$ with the side length of $8.12 \AA$. (e) Third layer ten-membered ring $\mathrm{Au}_{10}$ with the side length of $5.13 \AA$. 
a)

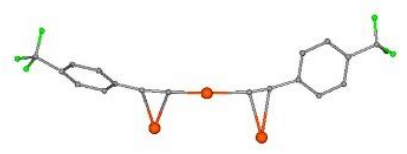

b)
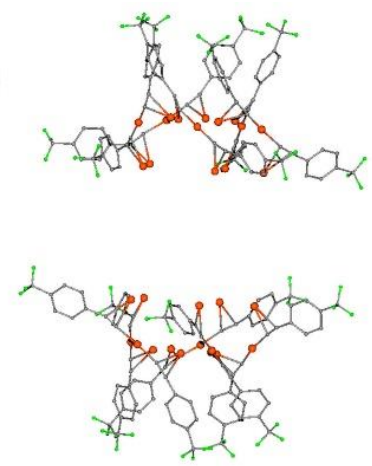

d)

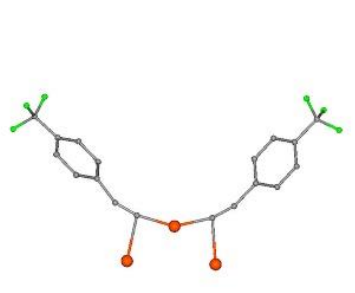

e)

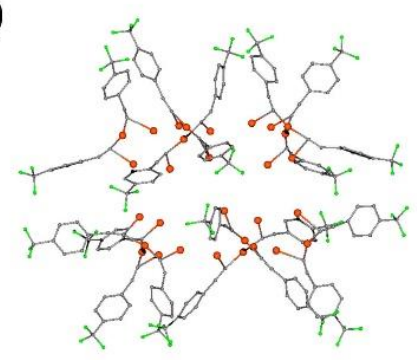

g)

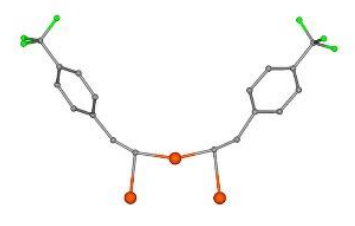

h)

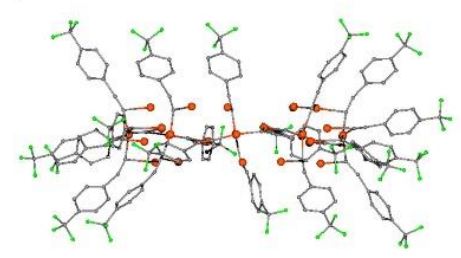

c)

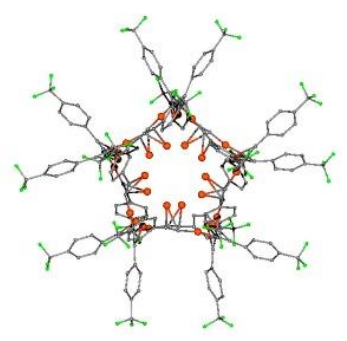

f)

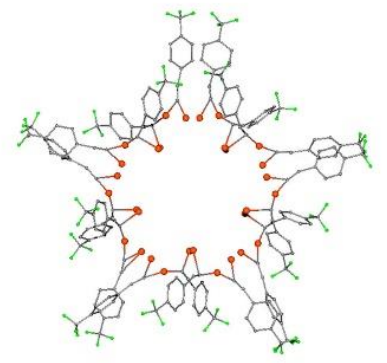

i)

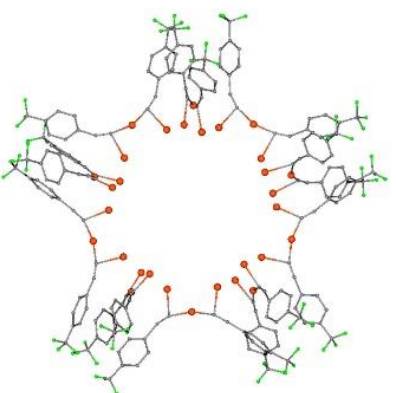

Figure S7. Two different alkynyl-gold coordination motifs found in $\mathbf{A} \mathbf{u}_{156}$ surface. (a) The alkynyl ligands adopted $\mu_{2}-\eta^{2}, \eta^{2}$ coordination mode in motif $A$, which connect with innermost shell $A_{4}$ and the second shell $\mathrm{Au}_{50}$. (b) and (c) The top and side views of motif A. (d) The alkynyl ligands adopted $\mu_{2}-\eta^{1}, \eta^{1}$ coordination mode in motif $\mathrm{B} 1$, which connect with second shell $\mathrm{Au}_{50}$ and the third shell $\mathrm{Au}_{30}$. (e) and (f) The top and side views of motif B1. (g) The alkynyl ligands adopted $\mu_{2}-\eta^{1}, \eta^{1}$ coordination mode in motif $\mathrm{B} 2$, which connect with the third shell $\mathrm{Au}_{30}$. (h) and (i) The top and side views of motif B2. 


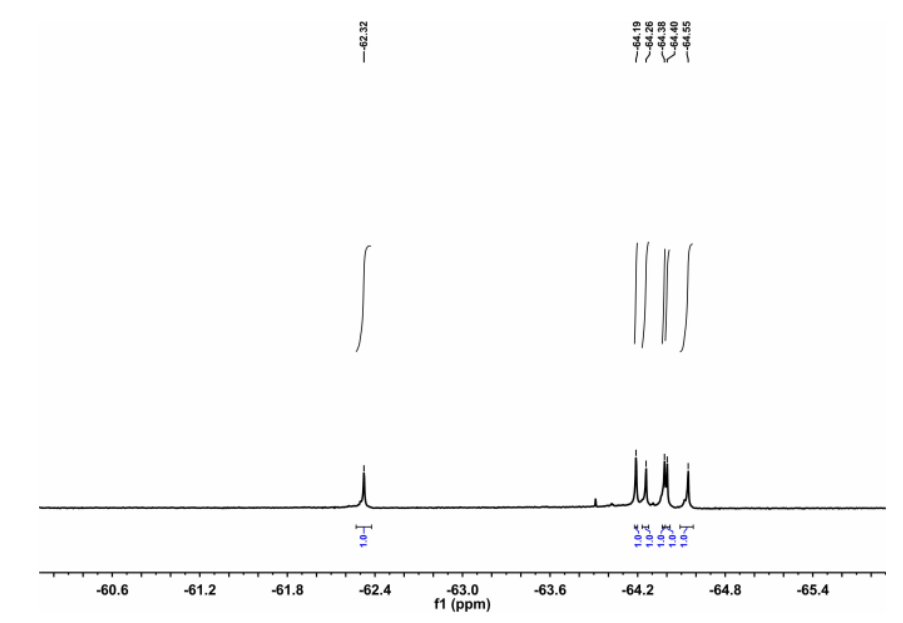

Figure S8. ${ }^{19} \mathrm{~F}$ NMR spectrum of $\mathbf{A u}_{156}$ in $\mathrm{CD}_{3} \mathrm{OD}$.

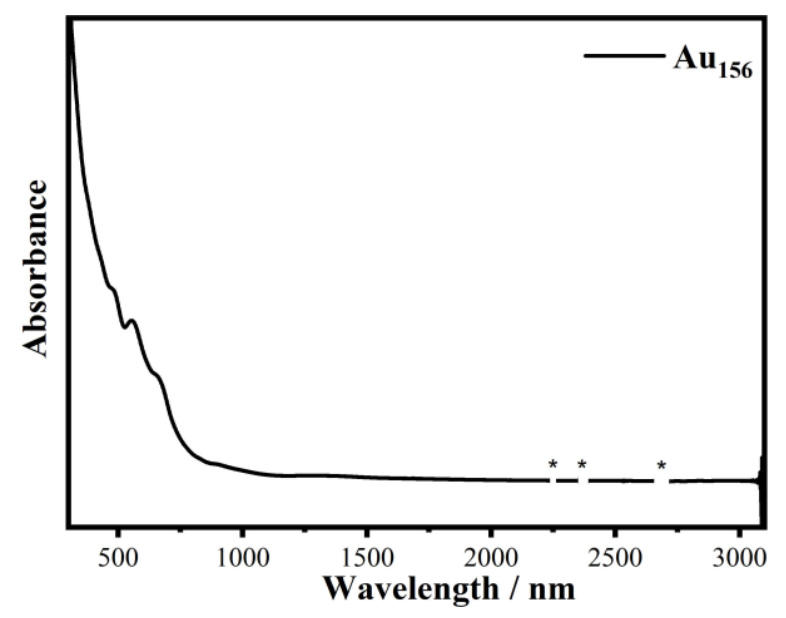

Figure S9. UV-Vis-NIR absorption spectrum of $\mathbf{A u}_{156}$ in $\mathrm{CH}_{2} \mathrm{Cl}_{2}$. The asterisks indicate the solvent absorption peak.
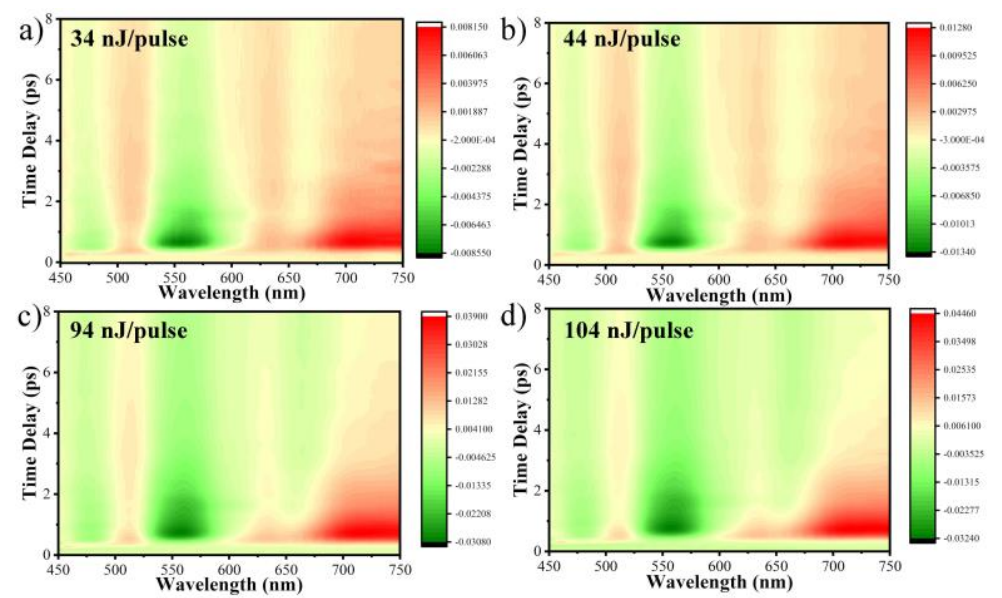

Figure S10. Transient absorption data maps pumped at $400 \mathrm{~nm}$ with pump power varying from 34,44 , 94 to $104 \mathrm{~nJ} /$ pulse. 


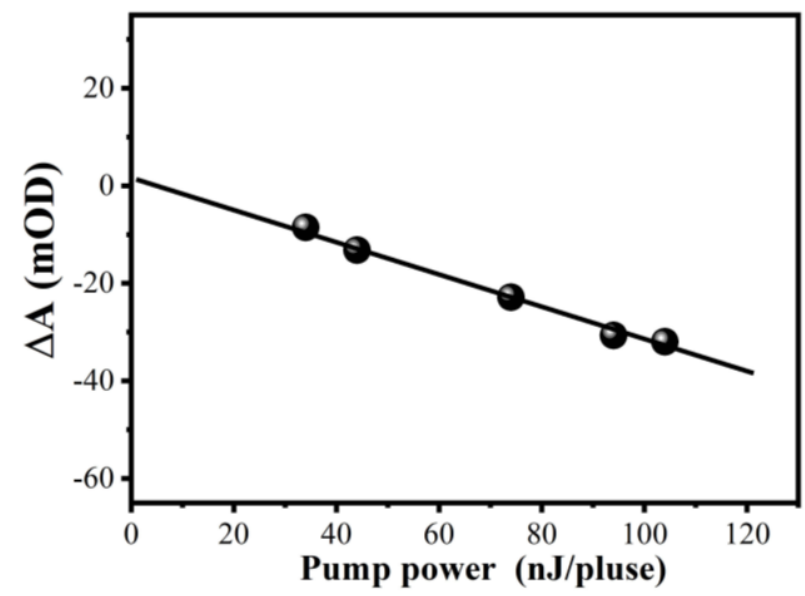

Figure S11. The relationship between the maximum intensity of GSB $(557 \mathrm{~nm})$ and pump power (the laser excitation pulse energy pumped at $400 \mathrm{~nm}$ ); the linear relationship excludes multiphoton effects or optical damage to the sample.

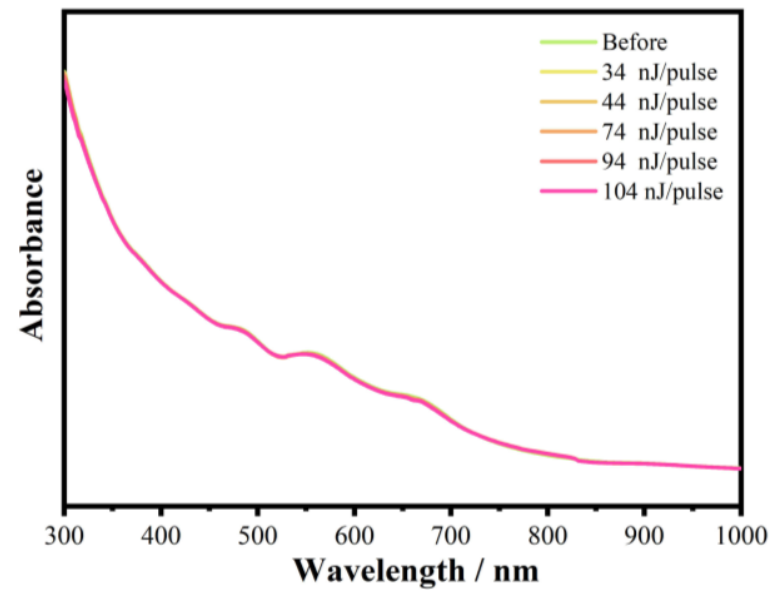

Figure S12. The UV-Vis absorption spectra of $\mathbf{A u}_{156}$ did not change before and after transient absorption experiments pumped at $400 \mathrm{~nm}$.

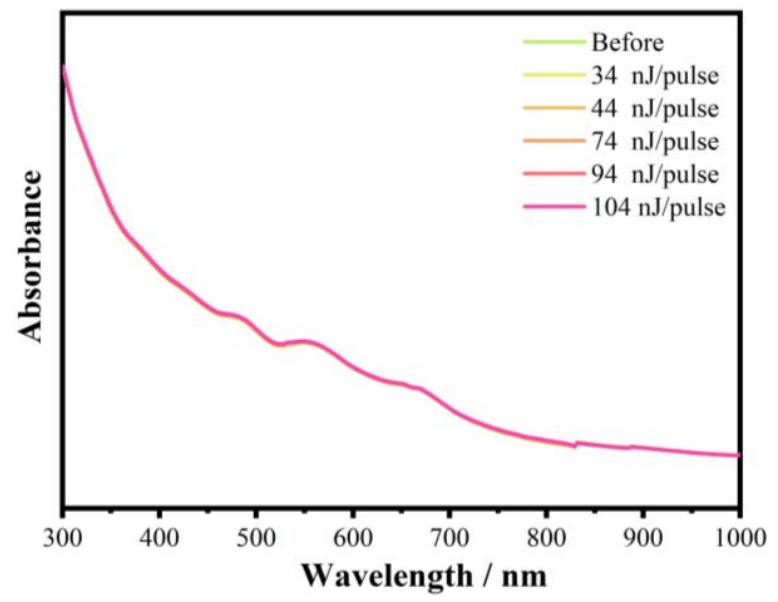

Figure S13. The UV-Vis absorption spectra of $\mathbf{A} \mathbf{u}_{156}$ did not change before and after transient absorption experiments pumped at $700 \mathrm{~nm}$. 


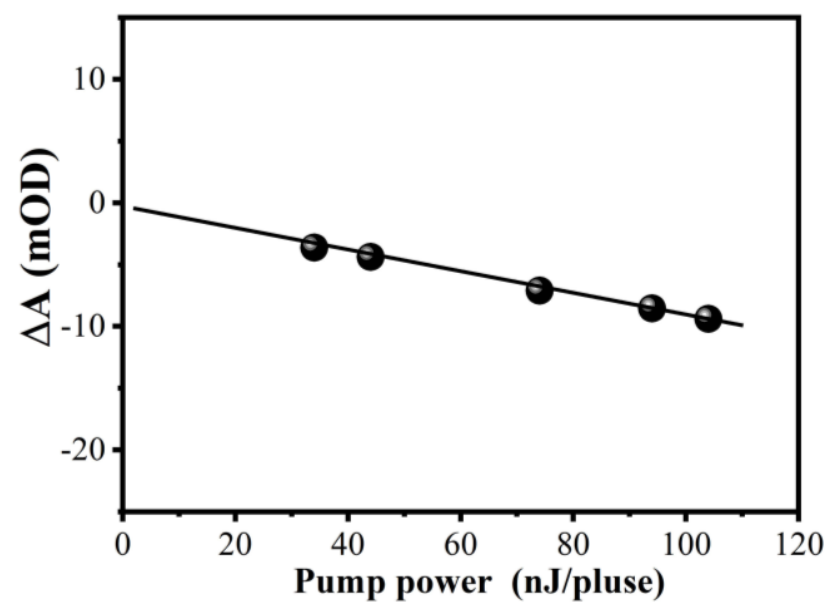

Figure S14. The relationship between the maximum intensity of GSB $(557 \mathrm{~nm})$ and pump power (the laser excitation pulse energy pumped at $700 \mathrm{~nm}$ ); the linear relationship excludes multiphoton effects or optical damage to the sample.
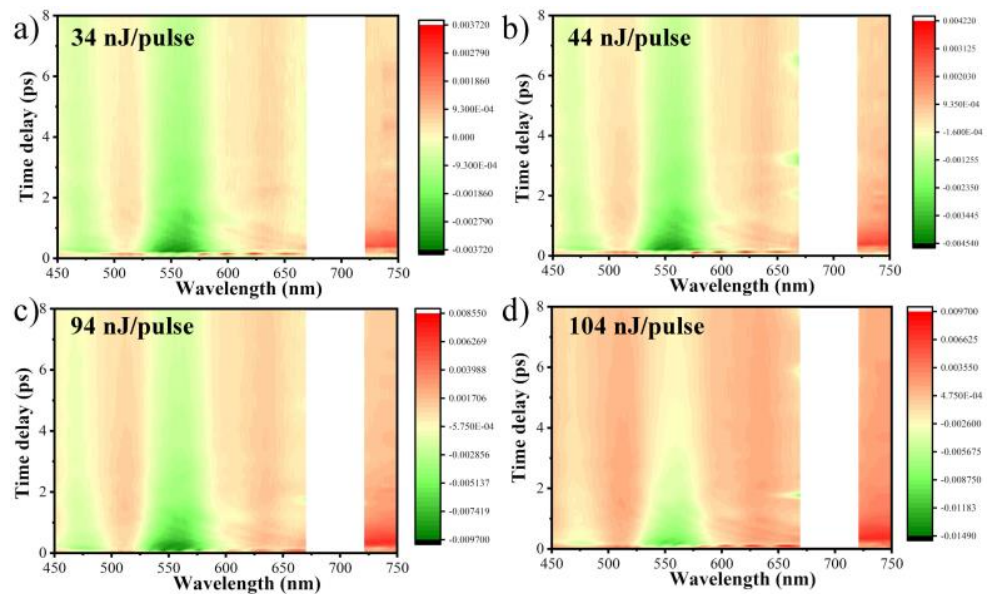

Figure S15. Transient absorption data maps pumped at $700 \mathrm{~nm}$ with pump power varying from 34,44 , 94 to $104 \mathrm{~nJ} / \mathrm{pulse}$. 

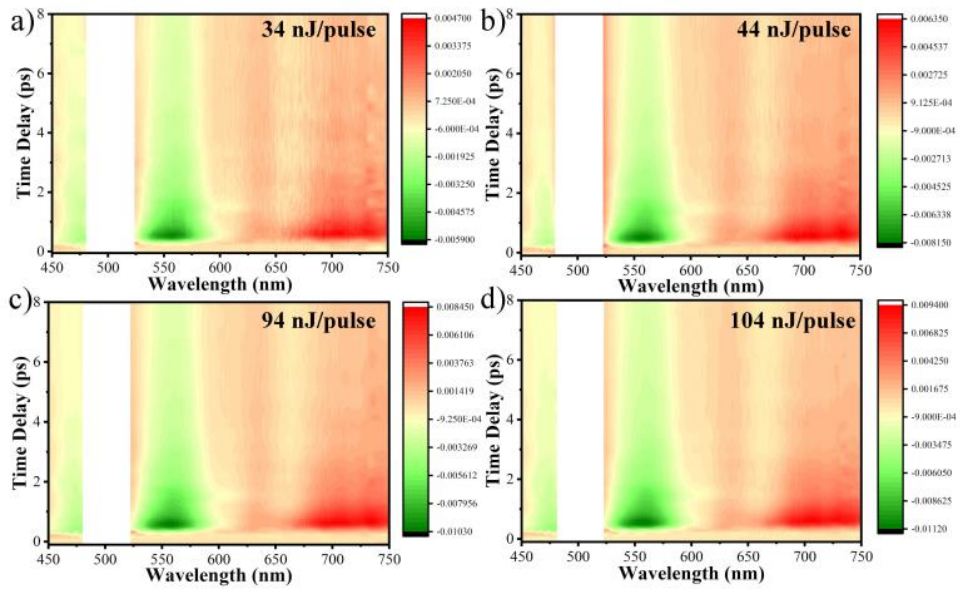

Figure S16. Transient absorption data maps pumped at $500 \mathrm{~nm}$ with pump power varying from 34,44 , 94 to $104 \mathrm{~nJ} /$ pulse.
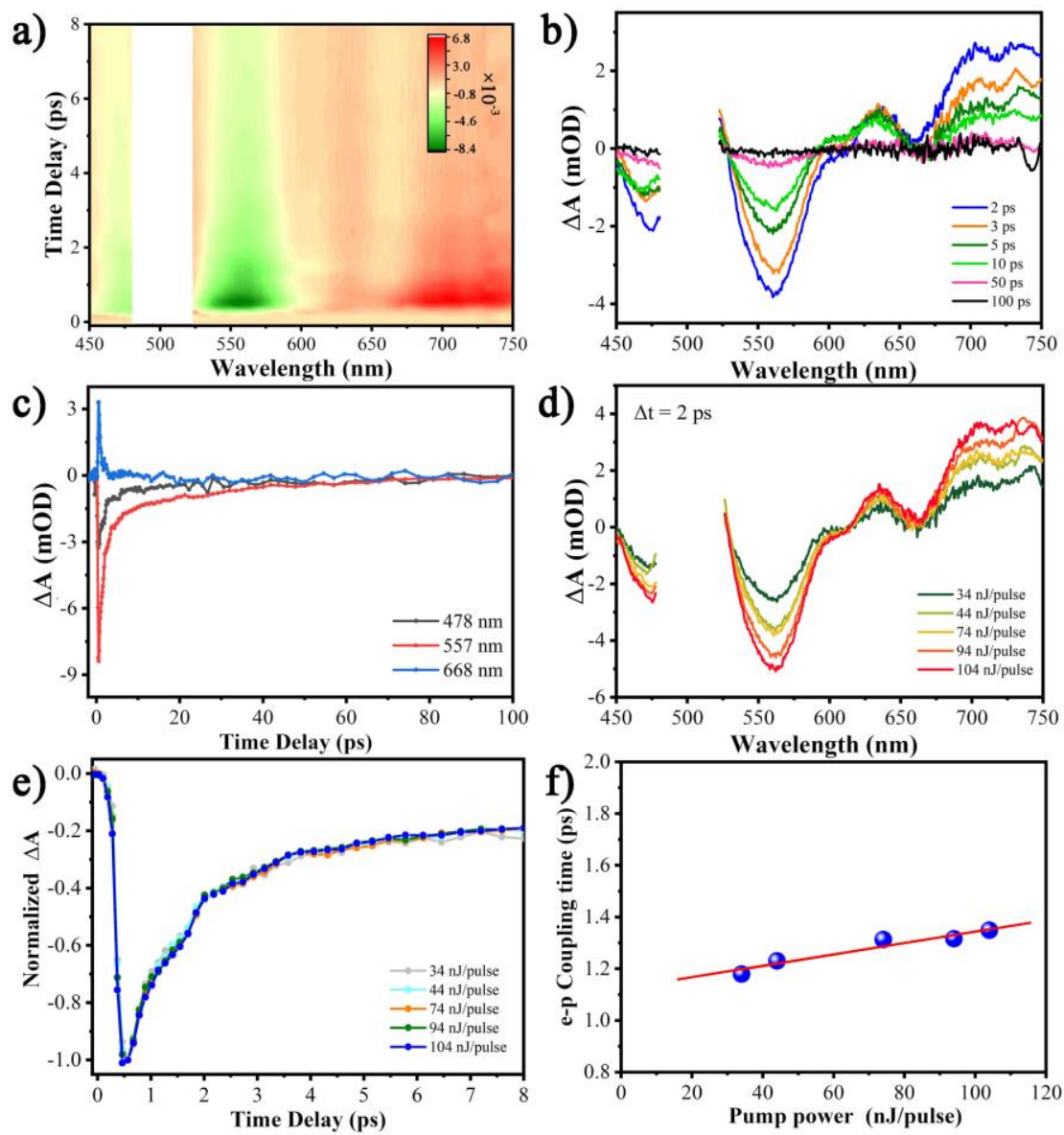

Figure 17. (a) Transient absorption data map of $\mathbf{A u}_{156}$ pumped at $500 \mathrm{~nm}$ in $\mathrm{CH}_{2} \mathrm{Cl}_{2}$. (b) TA spectra as a function of time delay between 2 and 100 ps. (c) Kinetics traces probed at selected wavelengths (pumped at $500 \mathrm{~nm}$ ). (d) TA spectra measured with different laser excitation pulse energies. (e) Normalized decay kinetics around $557 \mathrm{~nm}$ as a function of laser fluence. (f) Extracted $\tau_{\mathrm{e}-\mathrm{ph}} \mathbf{}$ of $\mathbf{A u}_{\mathbf{1 5 6}}$ as a function of 500-nm pump fluence. 


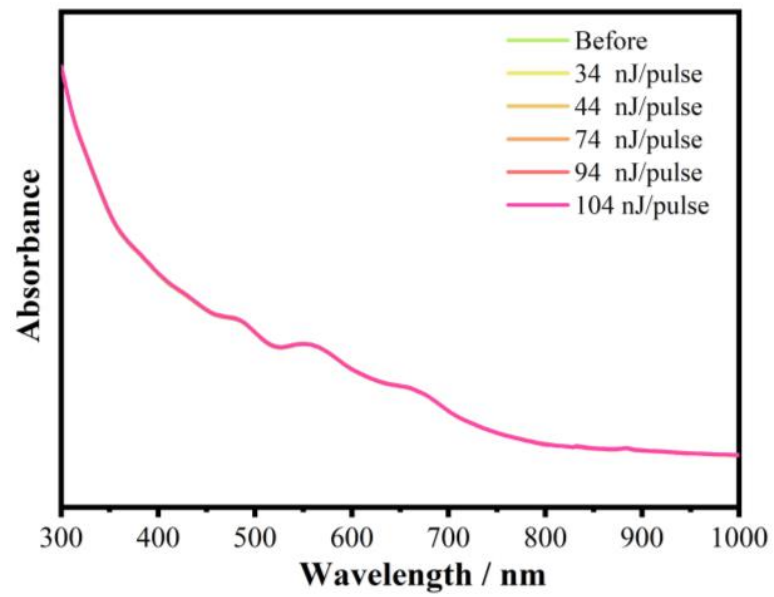

Figure S18. The UV-Vis absorption spectra of $\mathbf{A} \mathbf{u}_{156}$ did not change before and after transient absorption experiments pumped at $500 \mathrm{~nm}$.

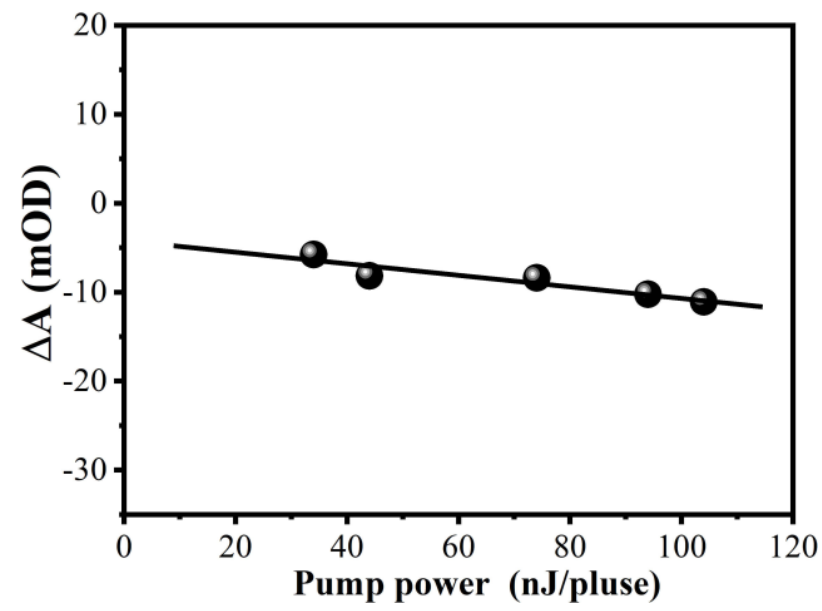

Figure S19. The relationship between the maximum intensity of GSB $(557 \mathrm{~nm})$ and pump power (the laser excitation pulse energy pumped at $500 \mathrm{~nm}$ ); the linear relationship excludes multiphoton effects or optical damage to the sample.
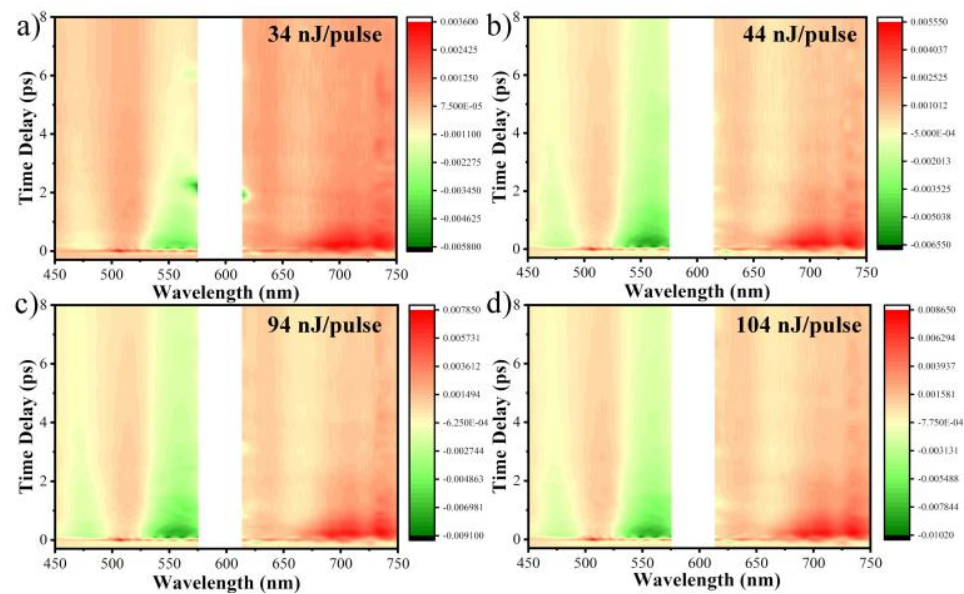

Figure S20. Transient absorption data maps pumped at $600 \mathrm{~nm}$ with pump power varying from 34 , 44, 94 to $104 \mathrm{~nJ} /$ pulse. 

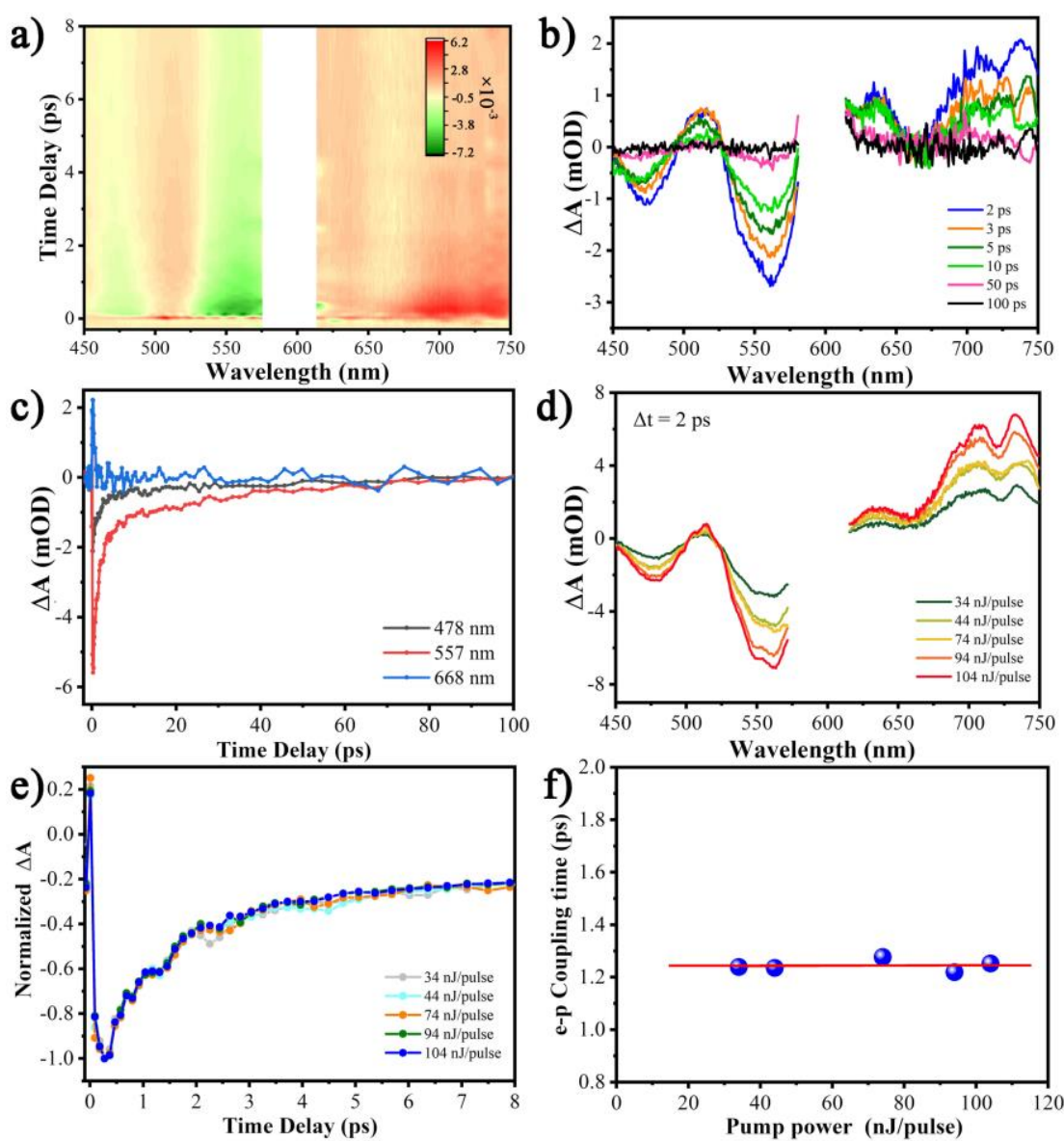

Figure 21. (a) Transient absorption data map of $\mathbf{A u}_{156}$ pumped at $600 \mathrm{~nm}$ in $\mathrm{CH}_{2} \mathrm{Cl}_{2}$. (b) TA spectra as a function of time delay between 2 and 100 ps. (c) Kinetics traces probed at selected wavelengths (pumped at $600 \mathrm{~nm}$ ). (d) TA spectra measured with different laser excitation pulse energies. (e) Normalized decay kinetics around $557 \mathrm{~nm}$ as a function of laser fluence. (f) Relaxation time constants of $\mathbf{A u}_{156}$ plotted versus the laser excitation pulse energy.

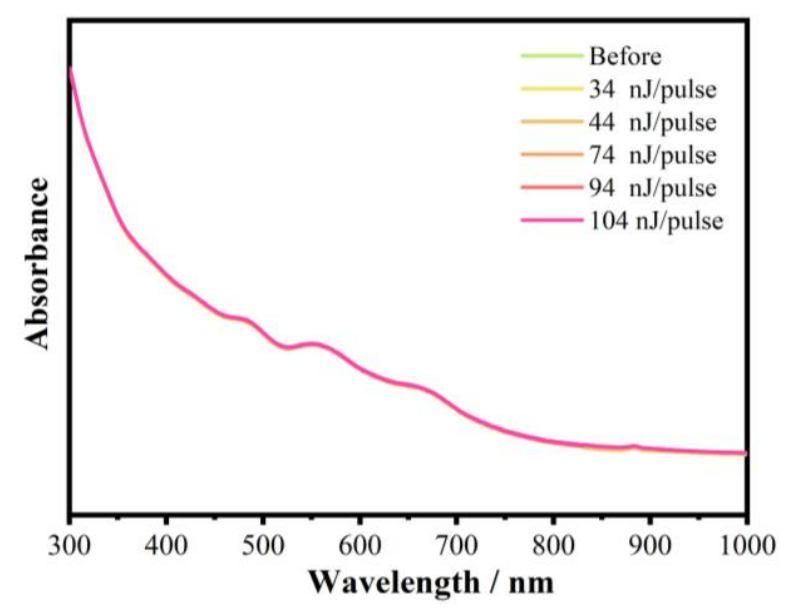

Figure S22. The UV-Vis absorption spectra of $\mathbf{A} \mathbf{u}_{156}$ did not change before and after transient absorption experiments pumped at $600 \mathrm{~nm}$. 


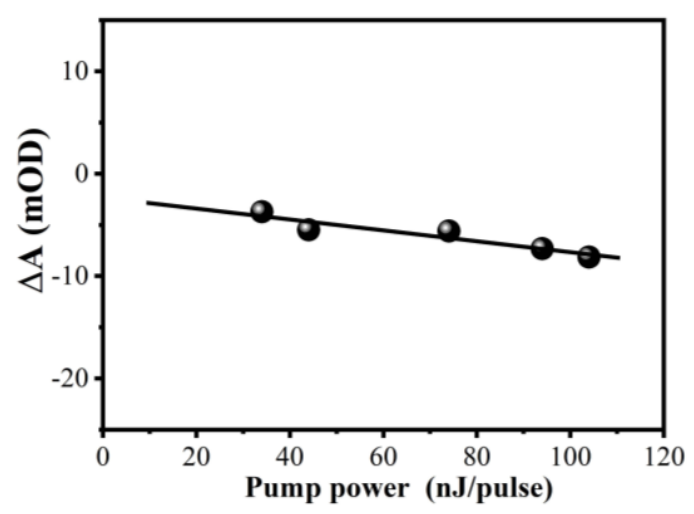

Figure S23. The relationship between the maximum intensity of GSB $(557 \mathrm{~nm})$ and pump power. (the laser excitation pulse energy pumped at $600 \mathrm{~nm}$ ); the linear relationship excludes multiphoton effects or optical damage to the sample.

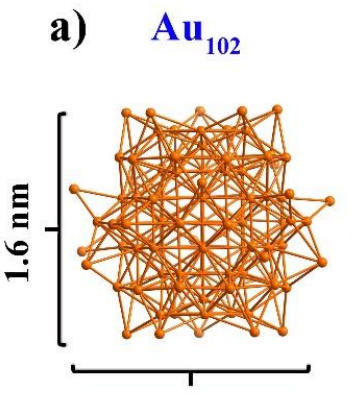

$1.8 \mathrm{~nm}$ b) $\quad \mathbf{A u} u_{103}$

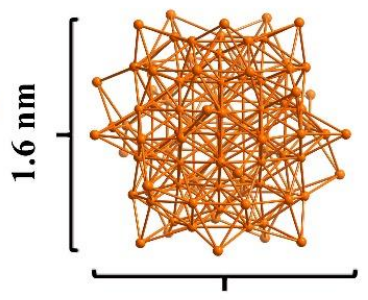

$1.8 \mathrm{~nm}$

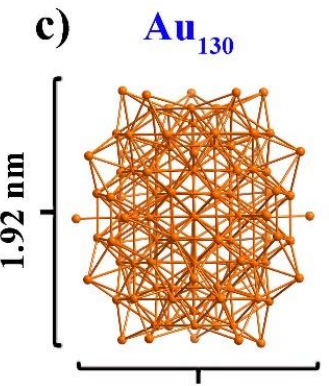

$1.8 \mathrm{~nm}$
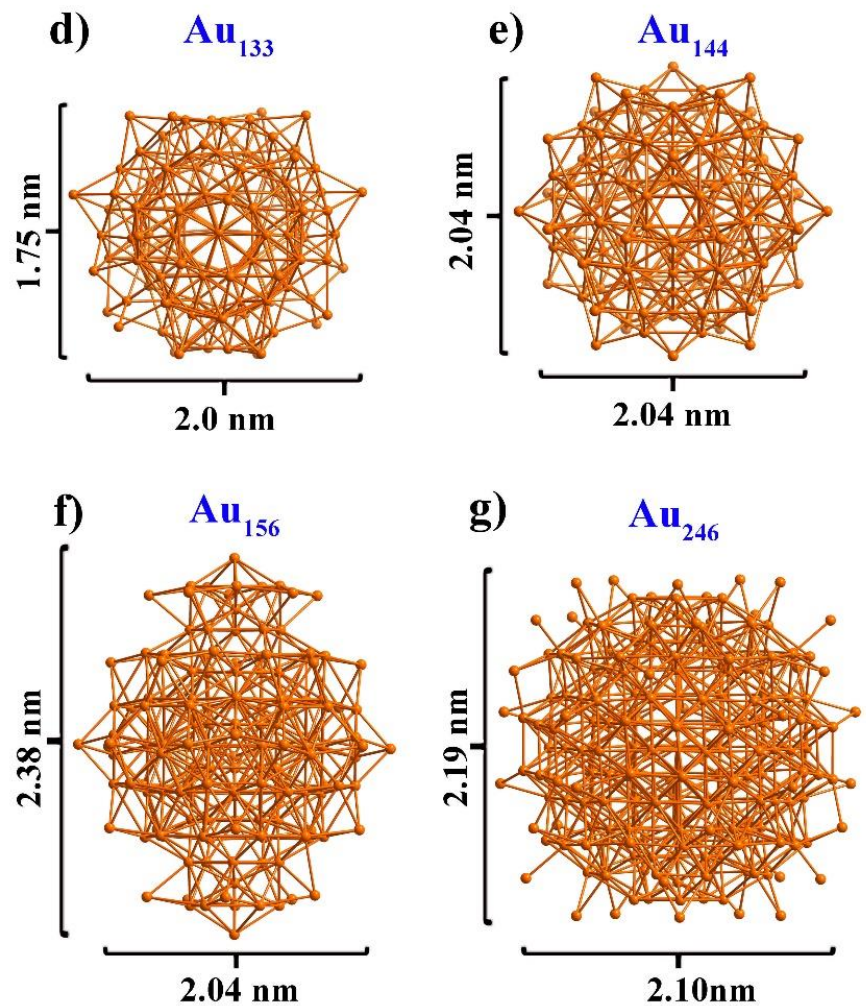

Figure S24. The metal kernel of Au nanoclusters in core-shell structure. (a) The view of kernel of $\mathrm{Au}_{102}(\mathrm{SR})_{44}$. (b) The view of kernel of $\mathrm{Au}_{103} \mathrm{~S}_{2}(\mathrm{SR})_{41}$. (c) The view of kernel of $\mathrm{Au}_{130}(\mathrm{SR})_{50}$. (d) The view of kernel of $A_{133}(\mathrm{SR})_{52}$. (e) The view of kernel of $\mathrm{Au}_{144}(\mathrm{C} \equiv \mathrm{CR})_{60}$. (f) The view of kernel of $\mathbf{A u}_{156 .}$ (g) The view of kernel of $\mathrm{Au}_{246}(\mathrm{SR})_{80}$. 


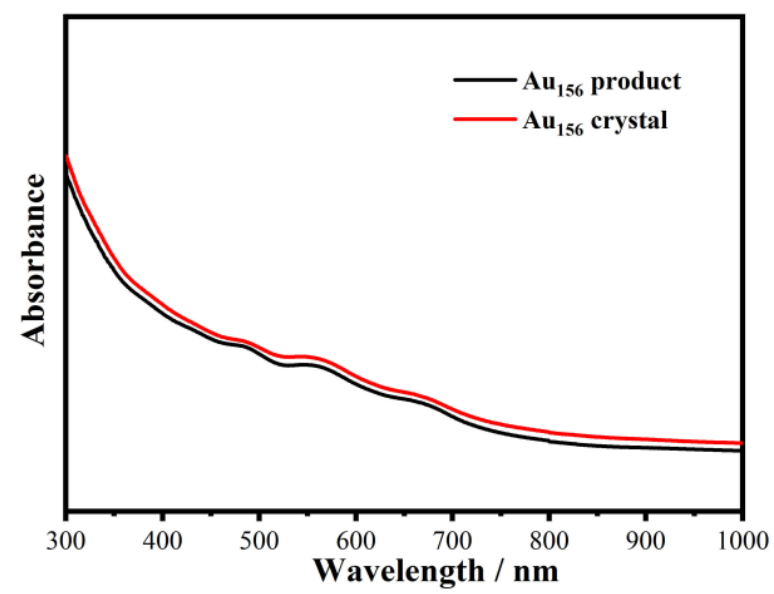

Figure S25. UV-Vis absorption spectra of $\mathbf{A u}_{156}$ products and $\mathbf{A} \mathbf{u}_{156}$ crystals in $\mathrm{CH}_{2} \mathrm{Cl}_{2}$ solution at room temperature.

a)

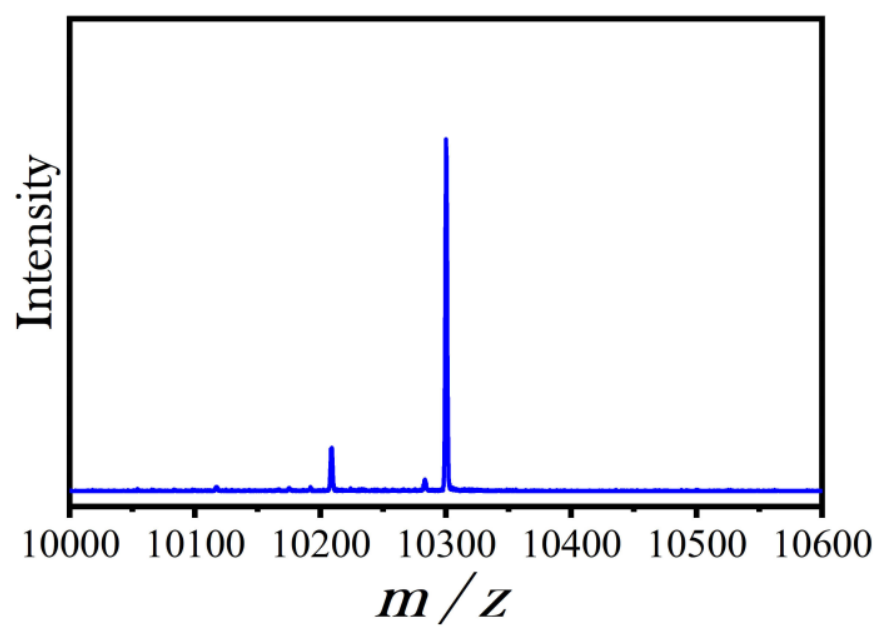

b)

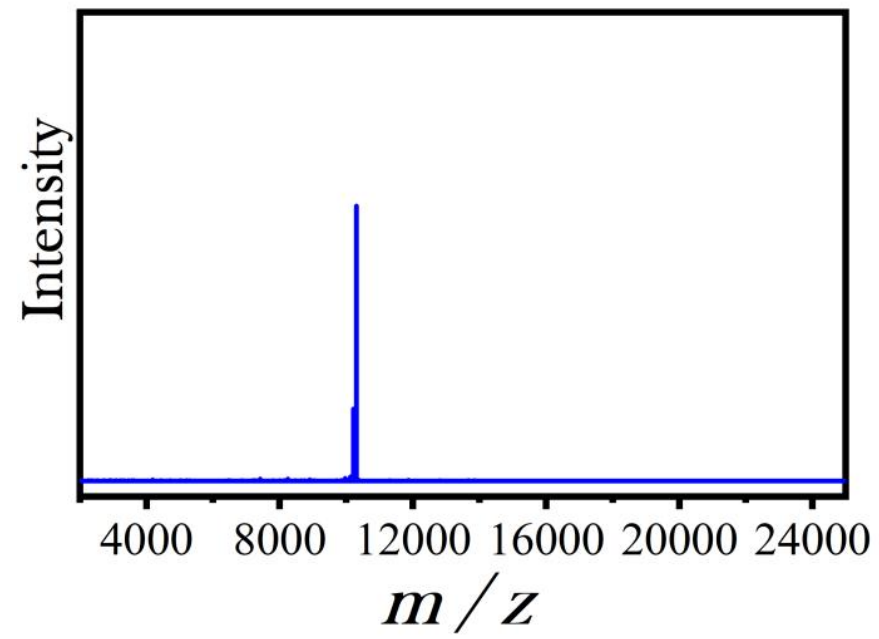

Figure S26. ESI-TOF-MS of $\mathbf{A} \mathbf{u}_{156}$ products in negative mode. a) The two peaks at 10207.1 and 10298.5 correspond to $\left[\mathrm{Au}_{156}(\mathrm{C} \equiv \mathrm{CR})_{59} \mathrm{ClCH}_{2} \mathrm{Cl}_{2} \mathrm{H}_{2}\right]^{4-}\left\{\left[\mathrm{Au}_{156}(\mathrm{C} \equiv \mathrm{CR})_{59} \mathrm{Cl}\right]^{6-}+\mathrm{CH}_{2} \mathrm{Cl}_{2}+2 \mathrm{H}^{+}\right\}$and $\left[\mathrm{Au}_{157}(\mathrm{C} \equiv \mathrm{CR})_{60} \mathrm{ClCH}_{2} \mathrm{Cl}_{2} \mathrm{H}_{2}\right]^{4-}\left\{\left[\mathrm{Au}_{156}(\mathrm{C} \equiv \mathrm{CR})_{60}\right]^{6-}+\mathrm{AuCl}+\mathrm{CH}_{2} \mathrm{Cl}_{2}+2 \mathrm{H}^{+}\right\}$, respectively. b) The measured full range spectrum. 
Table S1. A summary of Au-Au bond lengths in $\mathbf{A u} \mathbf{u}_{156}$ nanoclusters.

\begin{tabular}{ccc}
\hline Species & The range length of Au-Au bond & The average lengths of Au-Au bond \\
\hline Shell 1 & $2.725 \sim 3.031 \AA$ & $2.816 \AA$ \\
1st and 2nd & $2.736 \sim 2.957 \AA$ & $2.854 \AA$ \\
Shell 2 & $2.771 \sim 3.131 \AA$ & $2.908 \AA$ \\
\hline 2nd and 3rd & $2.759 \sim 3.387 \AA$ & $2.878 \AA$ \\
Shell 3 & $2.923 \sim 3.196 \AA$ & $3.040 \AA$ \\
\hline 1st and 4th & $2.914 \sim 3.338 \AA$ & $3.063 \AA$ \\
\hline 2nd and 4th & $2.803 \sim 3.100 \AA$ & $2.956 \AA$ \\
\hline 3rd and 4th & & $2.886 \AA$ \\
\hline
\end{tabular}

Table S2. A summary of $\mathrm{Au}-\mathrm{C}$ bond lengths in $\mathbf{A} \mathbf{u}_{156}$ nanoclusters.

Species The range length of $\mathrm{Au}-\mathrm{C}$ bond The average lengths of $\mathrm{Au}-\mathrm{C}$ bond

$\begin{array}{llc}\text { Motif A } & 1.835 \sim 2.483 \AA & 2.188 \AA \\ \text { Motif B1 } & 1.901 \sim 2.362 \AA & 2.092 \AA \\ \text { Motif B2 } & 1.886 \sim 2.357 \AA & 2.097 \AA\end{array}$


Table S3. Delay lifetime of $\mathbf{A} \mathbf{u}_{156}$ obtained from biexponential fitting on femtosecond transient absorption measurement with $400 \mathrm{~nm}$ laser excitation.

\begin{tabular}{c|cc|cc}
\hline $\begin{array}{c}\text { Pulse energy } \\
\text { (nJ/pulse) }\end{array}$ & $\boldsymbol{\tau}_{\mathbf{1}}$ (ps) & Confidence Int. (ps) & $\boldsymbol{\tau}_{\mathbf{2}}$ (ps) & Confidence Int. (ps) \\
\hline $\mathbf{3 4}$ & 1.24 & 0.06 & 24.1 & 2.6 \\
$\mathbf{4 4}$ & 1.31 & 0.05 & 27.7 & 2.0 \\
$\mathbf{7 4}$ & 1.45 & 0.06 & 32.5 & 2.3 \\
$\mathbf{9 4}$ & 1.58 & 0.07 & 37.8 & 3.5 \\
$\mathbf{1 0 4}$ & 1.60 & 0.08 & 44.0 & 4.6 \\
\hline
\end{tabular}

Table S4. Time constants of $\mathbf{A} \mathbf{u}_{156}$ obtained from biexponential fitting on femtosecond transient absorption measurement with $700 \mathrm{~nm}$ laser excitation.

\begin{tabular}{c|cc|cc}
\hline $\begin{array}{c}\text { Pulse energy } \\
\text { (nJ/pulse) }\end{array}$ & $\boldsymbol{\tau}_{\mathbf{1}}$ (ps) & Confidence Int. (ps) & $\boldsymbol{\tau}_{\mathbf{2}}$ (ps) & Confidence Int. (ps) \\
\hline $\mathbf{3 4}$ & 1.16 & 0.27 & 26.1 & 5.3 \\
$\mathbf{4 4}$ & 1.14 & 0.19 & 25.8 & 3.9 \\
$\mathbf{7 4}$ & 1.15 & 0.12 & 23.3 & 2.7 \\
$\mathbf{9 4}$ & 1.15 & 0.24 & 26.7 & 6.5 \\
$\mathbf{1 0 4}$ & 1.16 & 0.15 & 25.8 & \\
\hline
\end{tabular}


Table S5. Time constants of $\mathbf{A u}_{156}$ obtained from biexponential fitting on femtosecond transient absorption measurement with $500 \mathrm{~nm}$ laser excitation.

\begin{tabular}{c|cc|cc}
\hline $\begin{array}{c}\text { Pulse energy } \\
\text { (nJ/pulse) }\end{array}$ & $\boldsymbol{\tau}_{\mathbf{1}}$ (ps) & Confidence Int. (ps) & $\boldsymbol{\tau}_{\mathbf{2}}$ (ps) & Confidence Int. (ps) \\
\hline $\mathbf{3 4}$ & 1.17 & 0.11 & 24.8 & 3.2 \\
$\mathbf{4 4}$ & 1.23 & 0.07 & 27.1 & 2.7 \\
$\mathbf{7 4}$ & 1.31 & 0.08 & 29.1 & 3.0 \\
$\mathbf{9 4}$ & 1.31 & 0.07 & 31.1 & 3.3 \\
$\mathbf{1 0 4}$ & 1.34 & 0.08 & 31.9 & 3.5 \\
\hline
\end{tabular}

Table S6. Delay lifetime of $\mathbf{A} \mathbf{u}_{156}$ obtained from biexponential fitting on femtosecond transient absorption measurement with $600 \mathrm{~nm}$ laser excitation.

\begin{tabular}{c|cc|cc}
\hline $\begin{array}{c}\text { Pulse energy } \\
\text { (nJ/pulse) }\end{array}$ & $\boldsymbol{\tau}_{\mathbf{1}}$ (ps) & Confidence Int. (ps) & $\boldsymbol{\tau}_{\mathbf{2}}$ (ps) & Confidence Int. (ps) \\
\hline $\mathbf{3 4}$ & 1.23 & 0.38 & 24.8 & 16.9 \\
$\mathbf{4 4}$ & 1.23 & 0.26 & 29.2 & 7.8 \\
$\mathbf{7 4}$ & 1.27 & 0.30 & 29.8 & 9.8 \\
$\mathbf{9 4}$ & 1.21 & 0.24 & 27.1 & 7.6 \\
$\mathbf{1 0 4}$ & 1.25 & 0.25 & 27.2 & 7.7 \\
\hline
\end{tabular}

